\title{
PENSAR CON VICO
}

\section{Rosario Diana \\ (ISPF, CNR)}

RESUMEN: Aspectos puntuales del pensamiento viquiano que han guiado mi investigación, y mis actividades audiovisuales.

Palabras ClaVE: Vico, 350 Aniversario, instalación audio-visual, autobiografía, R. Diana.

\section{Thinking with Vico}

ABSTRACT: Specific aspects of Viquian thought that have guided my research, and my audiovisual activities.

KeYwords: Vico, $350^{\text {th }}$ Anniversary, audio-visual installation, autobiography, R. Diana.

\section{Pensare con Vico}

RIASSUNTO: Nel presente contributo espongo aspetti puntuali del pensiero vichiano che hanno guidato la mia ricerca dell'Autore, nonché mie attività audiovisive.

PAROLE CHIAVE: Vico, $350^{\circ}$ Anniversario, installazione audio-visiva, autobiografia, R. Diana.

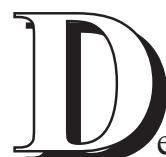

ebo aclarar enseguida que no soy ni un viquista (como solo puede serlo quien decida empeñar la mayor parte de sus propias energías intelectuales en el estudio del filósofo napolitano, convirtiéndose así en un "especialista”) ni un frecuentador asiduo de las páginas viquianas: dos figuras de investigador hacia las cuales tengo gran respeto, la mayoría de las veces unido a admiración. Más sumisamente me limito a reconocer que en mi itinerario de investigación -en el que creo que se manifiesta una direccionalidad centrada más sobre cuestiones teóricas que sobre la exégesis de un único autor- algunos puntuales aspectos del pensamiento viquiano han representado el punto de partida de la investigación, suministrando luego, en algún caso, incluso la idea-guía.

Este artículo responde a una invitación expresa por parte de la Dirección de la Revista para este volumen especial por el $350^{\circ}$ Aniversario del nacimiento de G. Vico, habiendo superado los criterios de valoración y del proceso de aceptación. 
He preferido articular esquemáticamente mi breve excursus en tres apartados: Pasado, Presente, Futuro. En ellos intentaré describir brevemente mis investigaciones viquianas referidas -naturalmente a partir de mi actividad actual-a los tres diferentes momentos temporales.

\section{Pasado}

En 2004 se publicó mi primer trabajo "viquiano", dedicado a la autobiografía del filósofo (Ragione narrativa ed elaborazione dialogica del sapere. L'autobiografia di Giambattista Vico e il suo contenuto problematico). ${ }^{1}$ En un apéndice al ensayo reedité el Progetto ai Letterati d'Italia per scrivere e loro Vite de Giovanàrtico di Porcìa, que -como es sabido- está en el origen de la Vita viquiana y nunca se volvió a publicar después de su primera salida en $1728 .{ }^{2}$ La versión completa -ampliada, con la bibliografía actualizada y unida a otros dos escritos míos sobre la autobiografía de Croce y de Silvio Pellico- ${ }^{3}$ se incluyó en mi libro Configurazioni filosofiche di sè. Studi sull'autobiografia intellettuale di Vico e Croce ${ }^{4}$ Gracias a esta investigación sobre las escrituras de vida me familiaricé con una modalidad de comunicación filosófica alternativa a las acostumbradas formas apodícticas de la tratadística teórica; una modalidad caracterizada por la autorrepresentación de un pensamiento en su hacerse, que al mismo tiempo se traduce en acción y práctica de vida y apunta a la exhortación, más o menos implícita, dirigida al lector, a compartir libremente y quizá a repetir, en todo o en parte -adecuándolo oportunamente a sí mismo- el itinerario existencial e intelectual del autografiado. El contacto directo con las autobiografías de Vico, Croce y Pellico representó para mí un verdadero laboratorio de reflexión y de experiencia, utilísimo para proceder a continuación en mi investigación que, atendiendo mientras tanto a las urgencias de la realidad contemporánea, encontraba su propio centro de interés en el análisis de las estructuras fundamentales de la identidad individual de modo cada vez más intercultural. 5

Una vivencia análoga fue el resultado de mi segundo encuentro con Vico: un ensayo sobre el Liber metaphysicus (1710) titulado Depotenziamento del "cogito" e "disappartenenza" dell'Io. In margine al "De antiquissima". Publicado en $2010,{ }^{6}$ también fue luego retomado -con adendas explicativas en el título (Depotenziamento del "cogito" cartesiano e "disappartenenza" dell'Io. In margi-

1. En Bollettino del Centro di studi vichiani, XXXIV, pp. 131-161.

2. Ibíd., pp. 162-167.

3. Los textos de referencia fundamentales para estos dos ensayos fueron, respectivamente, el Contributo alla critica di me stesso (1915) de Benedetto Croce y Le mie prigioni (1832) de Silvio Pellico.

4. Edizioni di Storia e Letteratura, Roma, 2013.

5. Cfr. R. DiAna, Identità individuale e relazione intersoggettiva. Saggi di filosofia interculturale, Aracne, Roma, 2013; en particular: Sección I Strumenti, pp. 15-50.

6. En el Bollettino del Centro di studi vichiani, XL, pp. 115-124. 
ne al "De antiquissima" di Giambattista Vico), ampliaciones y actualizaciones bibliográficas- en mi libro Disappartenenza dell'Io. Filosofia e musica verso Samuel Beckett. ${ }^{7}$ En este trabajo viquiano mío se encuentra, en realidad, la fuente del paradigma teórico que gobierna y conecta entre ellas la investigación filosófica y la musical presentadas en el volumen. En efecto -he aquí en síntesis la tesis argumentada en el escrito en cuestión- fiel a su criterio del verum-factum, según el cual se puede conocer solo aquello que nosotros mismos hacemos, Vico afirma -contra Descartes- que del Yo, sujeto del cogito, no se puede tener conocimiento, sino solo conciencia. Puesto que el Yo, al cual en la experiencia ordinaria atribuimos nuestras acciones (Yo escribo, Yo como, Yo firmo el contrato) y que tendemos a identificar como nuestro núcleo más auténtico, construyéndose y modificándose en el transcurso de la propia historia, en origen no se "hizo" por sí mismo: no surge, sino que se encuentra. Excluido de la topografía del facere humano, el Yo aparece como propio y extraño al mismo tiempo, y por tanto no perteneciente a sí mismo. Así delineada, esta condición del Yo se convierte en el eje conceptual de un diálogo filosófico y musical a distancia con algunas obras beckettianas (Murphy, Final de partida, La última cinta de Krapp, Film, No Yo, Aquella vez, Mecedora, Ohio Impromptu).

\section{Presente}

Actualmente estoy empeñado en la investigación para la redacción de un ensayo conectado a una instalación "viquiana" -titulada Voci da una "Vita". Un'esecuzione di brani dalla "Vita di Giambattista Vico scritta da se medesimo" (1723-28) - comisariada por mí a petición del Instituto (Ispf-Cnr) y de la Administración comunal de Nápoles para la celebración del $350^{\circ}$ Aniversario del nacimiento del filósofo napolitano. He trabajado en este proyecto con la escenógrafa Nera Prota (profesora de Escenografía en la Academia de Bellas Artes de Nápoles) que, junto a sus alumnas Rebecca Carlizzi y Marianna Russo, ha proyectado la estructura, consistente en una serie de monolitos de madera de color negro, cuatro de los cuales estaban dotados de grandes monitores de audio-vídeo para la difusión de imágenes, palabras y sonidos. Yo me ocupé de elaborar el material para difundir en audio-vídeo. La instalación - de la cual se aporta a continuación una imagen- se expuso en Nápoles, en la Sala dell'Armeria del Maschio Angioino, del 7 de mayo al 10 de junio de 2018.

Desde el 2011 inicié una investigación experimental sobre la difusión de los contenidos de las ciencias humanas por medio de las artes audiovisuales, en cuyo

7. Editoriale scientifica, Nápoles, 2016. Al volumen se adjunta un CD (en realidad se trata de un libro-con-cd, para subrayar con esa operación el paralelismo entre filosofía y música) que reúne seis fragmentos musicales escritos sobre la base del paradigma de la no pertenencia del Yo de otros tantos compositores contemporáneos: Salvatore Carannante, Chiara Mallozzi, Lorenzo Pone, Rosalba Quindici, Bernardo Maria Sannino, Giancarlo Turaccio. 


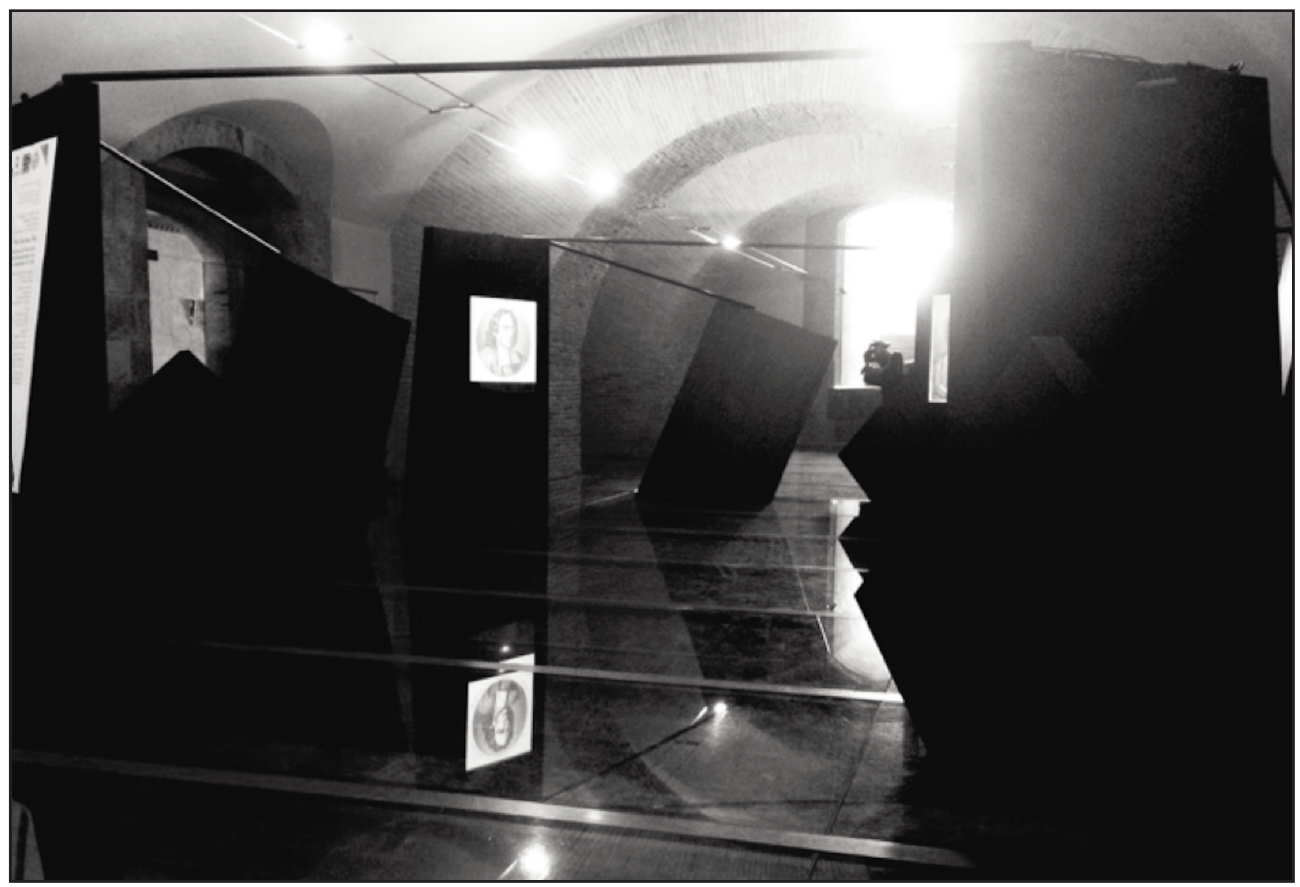

contexto se produjeron libros, ensayos, $\mathrm{CDs}^{8}$ y una veintena de lecturas filosóficas teatralizadas. El aniversario viquiano nos ha permitido, a mí y al grupo de trabajo que se ha creado conmigo, aplicar los presupuestos teóricos y los instrumentos operativos, puestos a punto a lo largo de los años, sobre los temas propios del pensador conmemorado. No pudiendo, ni queriendo, renegar de mi sustrato de estudioso de autobiografías, pensé utilizar los recursos técnico-estéticos ofrecidos por la natura-

8. R. Diana, La forma-reading. Un possibile veicolo per la disseminazione dei saperi filosofici. Resoconto ragionato, programma e strumenti di lavoro, Mimesis, Milán-Udine, 2015 (luego en Pagine Inattuali, 2016, 6, pp. 4575); R. Diana - N. Prota - V. NAsti, «Un teatro ideale per il reading filosofico», Research Trends in Humanities, III, 2016, pp. 14-27 (luego en F. GREGorio - G. D'ANNA - A.A. SANNA, Filosofia e pratiche dei saperi, Mimesis, Milán-Udine, 2016, pp. 61-75); R. Diana - D. Giugliano - N. ProtA, «Il buio oltre la zattera. Progetto per un reading filosofico», Endoxa, I, mayo 2016, 1, pp. 1-12; M. CAMBi - V. Chiore - R. Diana - R. Evangelista - D. Giugliano - V. NAsti - N. Prota - M. Russo - M. SAnNA - A. Stile, Le naufrage de l'humanité. Riflessioni a più voci sulle forme di deumanizzazione a partire dalla "Zattera della Medusa" di Théodore Géricault, cuaderno monográfico Think Tank de la revista anual online (open access) Research Trends in Humanities, IV, 2017, pp. 2-4; R. DiANA - R. QUINDICI - G. LoRUSSo, «Elogio della filosofia in forma di decalogo», en el CD: R. QUINDICI - G. Lorusso, Intersezioni, Stradivarius, Milán, 2017, pistas 1-2; G. CACCiatore - R. Diana - R. Evangelista - D. Giugliano - C. de Luzenberger - M. SAnna, Percorsi possibili per una riflessione filosofica contemporanea, a cargo de R. DianA, Mimesis, Milán-Udine, 2017; R. DiAnA, «Risonanza di concetti. A proposito del teatro-reading filosofico», en ID. - L.M. SiCCA - G. TuRACCio (a cargo de), Risonanze. Organizzazione Musica Scienze, Editoriale scientifica, Nápoles, 2017, pp. 153-162. R. DiAnA, «Phoné / Bene. Un'installazione per pensare», Research Trends in Humanities, V, 2018, pp. 65-69; ID., «L'eroismo dello studioso. Reading in forma di concerto per soli recitanti e coro di lettori», en F. Lomonaco (a cargo de), Eroicamente Vico. Medicina, vita civile e ragione poetica nel "De mente heroica", Aracne, Roma, 2018, pp. 37-54. 
leza de la instalación para realizar una presentación de la autobiografía viquiana que -"insólita" a sabiendas en la modalidad-pudiese revelarse (a mi modesto entender) eficaz para mostrar al público potencial los trazos fundamentales del personaje autografiado. Por consiguiente, seleccioné cuatro famosos fragmentos de la Vita viquiana. Cuatro importantes piezas - centradas cada una en un tema bien definido y funcional para los propósitos del autor- con las cuales Vico construyó la imagen de sí mismo que intentaba transmitir a sus contemporáneos y perpetuar para los epígonos. Cada episodio - al cual aquí por comodidad se dio un título- estaba asignado a un monolito dotado de un monitor audiovisual:

1. El infortunio predestinante.- La caída de niño, a la cual Vico atribuye el origen de su propio carácter "melancólico", síntoma -según una tradición que se remonta hasta Aristóteles- de genial predisposición hacia los estudios humanísticos. ${ }^{9}$

2. Maestro de sí mismo.- Con sutil autocomplacencia, el filósofo señala su obligada elección de una formación autodidacta. ${ }^{10}$

3. Preceptor en Vatolla.- Se evoca el periodo de estudio y de formación en soledad: un momento típico en la biografía de un pensador. ${ }^{11}$

9. «El señor Giambattista Vico nació en Nápoles el año 1670 de honestos padres, los cuales dejaron una muy buena fama de sí mismos. El padre era de humor alegre, la madre de temperamento bastante meláncolico, y así ambos contribuyeron a la naturaleza de este hijo suyo, de forma que de niño fue de gran vivacidad e inquieto. Pero a la edad de siete años, habiendo caído de cabeza desde lo alto de una escalera al suelo, donde permaneció durante sus buenas cinco horas inmóvil y sin sentido, y habiéndose quebrado la parte derecha del cráneo, sin romperse el pericráneo, por lo que, ocasionándole la fractura un tumor deforme, por los muchos y profundos cortes, el joven se desangró, por lo que el cirujano, viendo el cráneo roto, y considerando el prolongado debilitamiento, hizo el siguiente pronóstico: que moriría o quedaría idiota. Sin embargo el dictamen en niguna de las dos partes, gracias a Dios, se verificó, pero de la curada enfermedad provino que, en adelante, creciese con una naturaleza melancólica y áspera, cual debe ser la de los hombres ingeniosos y profundos que, por el ingenio, brillan con agudezas, por la reflexión no se deleitan con argucias y con lo falso». (Cfr. texto italiano en: G. VICO, Vita di Giambattista Vico scritta da se medesimo - 1723-1728 -, en ID., Opere, a cargo de A. BAtTistinI, Mondadori, Milán, 20113, 2 vols., I, p. 5. [N.T.: Trad. al castellano citada de: Moisés González García y Josep Martínez Bisbal (eds.), Autobiografía de Giambattista Vico, Siglo XXI Eds., Madrid, 1998, pp. 81-82]).

10. «Por tanto, tras una larga convalecencia que duró sus buenos tres años, se reintegró a la escuela de gramática, y puesto que terminaba rápidamente en casa lo que le mandaba el maestro, y creyendo el padre que tal rapidez fuese negligencia, un día preguntó al maestro si su hijo hacía los deberes como buen alumno, y habiéndole dicho que sí, le rogó que le doblase la tarea, excusándose, sin embargo, el maestro, porque él debía adaptarse al nivel de sus otros condiscípulos, y no podía organizar una clase para uno solo, y la otra era muy superior. Entonces, estando presente en tal charla el muchacho, con gran ardor rogó al maestro que le permitiese pasar a la clase superior, puesto que él supliría por su cuenta lo que le faltaba en medio por aprender. El maestro, más por experimentar de lo que fuese capaz un genio infantil, que porque pudiese lograrlo realmente, se lo permitió; y, con gran sorpresa por su parte, descubrió a los pocos días a un muchacho maestro de sí mismo. [...] [A]consejaron al padre que le mandase a los padres jesuitas, que le admitieron en la clase media. [...] [Pero] como si de una ofensa hecha a él mismo se tratase, Giambattista resentido [...] se marchó de aquella escuela y, encerrándose en casa, aprendió por sí mismo [...] lo que le quedó por aprender de los padres en la clase primera y en la de humanidades, y en el octubre siguiente comenzó a estudiar la lógica. Por entonces, siendo verano, él se ponía a estudiar por la noche, y su buena madre al despertarse del primer sueño, y pidiéndole por piedad que se fuese a dormir, muchas veces lo encontró estudiando hasta el amanecer. Lo cual venía a ser indicio de que, al ir avanzando en edad en medio del estudio de las letras, iba a defender con fuerza su vocación literaria». (Cfr. ed. de A. BatTistinI, cit., pp. 5-6. N.T.: trad. citada de M. GonZÁlez García y J. Martínez BisBal, cit., pp. 83-84).

11. «Andaba por entonces debilitándose su constitución física por la tisis, y por él se reducía de forma angustiosa el patrimonio familiar, y tenía un ardiente deseo de ocio para proseguir sus estudios y su ánimo aborrecía grandemente el estrépito del foro, cuando quiso la buena suerte que se encontrase dentro de una librería con monseñor Geronimo 
4. Los cuatro autores.- Se recuerdan los referentes teóricos fundamentales de la Scienza nuova: Platón, Tácito, Francis Bacon, Hugo Grocio. ${ }^{12}$

Los cuatro capítulos se difundían en audio con una sobria secuencia de imágenes constituida por los retratos típicos del filósofo y por los textos originales, con el fragmento de un manuscrito en filigrana; pero estos últimos desaparecían después de poquísimos segundos, impidiendo así al público completar su lectura, para exhortarlo de ese modo a escuchar la palabra más que a encontrarla en la página virtual. Al final de toda la operación, más importante era, sin embargo -respecto al componente icónico- el fondo sonoro subyacente, compuesto para la ocasión y constituido por una lectura rítmica susurrada de trozos del texto mismo intercalados con otros escritos por mí, en los cuales se emulaban reflexiones que Vico habría podido desarrollar mientras escribía su Vita. Sustancialmente, mi propósito era hacer audible -bajo el texto auténtico- el imaginario flujo de conciencia que podía haber precedido y acompañado la redacción de la página viquiana.

El contenido de la instalación nació primero como un producto audiovisual, sobre todo audio, como bien se deduce de lo que acabo de precisar. En este formato se presentó en preestreno, el 18 de enero de 2018, al "Premio Filosófico G. Vico" -edición 2018-, organizado por Fabrizio Lomonaco y Claudia Megale, con el patrocinio del Departamento de Estudios Humanísticos de la Universidad de Nápoles Federico II y del Consorcio interuniversitario "Civiltà del Mediterraneo". ${ }^{13}$

Rocca, obispo de Isquia, ilustrísimo jurisconsulto, como lo demuestran sus obras, con el que tuvo una conversación acerca del método correcto para enseñar la jurisprudencia. Monseñor quedó tan satisfecho que le indujo a que aceptase ir a enseñarla a sus sobrinos en un castillo en Cilento, lugar bellísimo y de aire purísimo, que pertenecía al señorío de un hermano suyo, el señor D. Domenico Rocca (que luego fue gentilísimo mecenas suyo [...]), porque le iba a tratar en todo igual que a sus hijos (como luego efectivamente le trató), y allí recobraría la salud con el aire puro del lugar y podría estudiar con toda comodidad. / Así sucedió, porque habiendo permanecido allí durante nueve años, hizo la mayor parte de sus estudios, profundizando en el de las leyes y en el del derecho canónico, a lo que le llevaba su obligación.» (Cfr. ed. de A. BattistinI, cit., pp. 11-12; trad. citada de M. GonzÁlez García y J. MARTínez BisBal, cit., pp. 90-91 [N.T.]).

12. «Por aquellos tiempos Vico admiraba a dos solamente por encima de todos los demás sabios, que fueron Platón y Tácito; porque con una mente metafísica incomparable Tácito contempla al hombre como es, Platón como debe ser. Y del mismo modo que Platón con aquella ciencia universal explora todos los aspectos de la honestidad, que terminan en un hombre lleno de un saber ideal, así Tácito desciende a todos los consejos de la utilidad, para que entre los infinitos e irregulares acontecimientos de la malicia y de la fortuna se conduzca bien el hombre con su sabiduría práctica. [...] [F]inalmente tuvo noticia de Francis Bacon, señor de Verulamio, hombre igualmente de incomparable sabiduría, tanto vulgar como refleja, como la de quien es al mismo tiempo un hombre universal en teoría y en práctica, así como raro filósofo y gran ministro de estado de Inglaterra. [...] [D]el mismo modo que Platón es el príncipe del saber de los griegos, y los griegos no tienen un Tácito, así un Bacon hace falta tanto a los latinos como a los griegos. Se admiraba de que un solo hombre fuese capaz de ver cuánto falta en el mundo de las letras, qué se debería descubrir y promover, y de cuántos y de cuáles defectos tenga que enmendarse en aquello que ya se tiene [...] Y habiéndose propuesto Vico tener siempre delante de los ojos a estos tres singulares autores, tanto en sus meditaciones como en sus escritos, de esa forma fue elaborando sus trabajos de ingenio [...]. [E]1 cuarto autor que debía añadirse a los otros tres que él había decidido para sí mismo [...] [,] Hugo Grocio [,] abarca en un sistema del derecho universal toda la filosofía y toda la filología [...]». (Cfr. ed. de A. BATTISTINI, cit., pp. 29-30 y 44; trad. citada de M. González García y J. Martínez Bisbal, cit., pp. 114-115 y 134 [N.T.]).

13. El audiovisual puede rescatarse en las siguientes direcciones web:

a) Ispf-Cnr: https://www.youtube.com/watch?v=M2qYvZGYTFk

b) Quidra: https://www.youtube.com/watch?v=A_vyiZxY-_c 
El ensayo que estoy preparando cerrará el proceso de investigación articulado -como es costumbre ahora para mí- en tres fases, cada una de las cuales aporta nuevos contenidos y métodos de conocimiento respecto a las demás: 1. Estudio preparatorio para la performance; 2. Realización de la performance; 3. Redacción del ensayo conclusivo e integrador de los diversos momentos. En él se publicarán también los textos añadidos por mí y el guión de todo el trabajo. Con este último resultado de mi actual investigación "viquiana" espero demostrar -en conexión con el precedente trabajo beckettiano- la no pertenencia del tiempo subjetivo (entendido como duración) y del mismo flujo de conciencia.

\section{Futuro}

A partir del año próximo tengo previsto trabajar en un libro teórico sobre la ética de las migraciones: un tema acerca del cual ya he publicado un ensayo programático ${ }^{14} \mathrm{y}$ he recogido diversos cuadernos de apuntes, unidos a una mole impresionante (sobre todo para mí) de referencias bibliográficas.

Como para el libro beckettiano, también en este caso el punto de partida será una reflexión sobre el pensamiento de Vico: específicamente sobre la cuestión del "sentido común". Sobre este punto la perspectiva viquiana-empírico-antropológica (por tanto, no transcendentalista) y declinada por círculos concéntricos de progresiva amplitud- permite, a mi modo de ver, elaborar un método igualmente empírico-antropológico para identificar, en general, una paradigmática comunidad de lo "humano": un conjunto mínimo de valores y necesidades compartidas, capaz de constituir una base funcional para implementar un reconocimiento recíproco entre sujetos culturalmente heterogéneos y en movimiento.

\section{[Traducción del italiano por María José Rebollo Espinosa]}

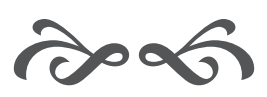

14. R. Diana, «La testa e il ventre. Linee fondamentali per un'etica delle migrazioni», en G. CACCIATORE - A. Giugliano (Eds.), Dimensioni filosofiche e storiche dell'interculturalità, Mimesis, Milán-Udine, 2014, pp. 73-80 (después, con ligeras modificaciones en el contenido y en el título: «Interculturalità e storia. Elementi per un'etica delle migrazioni», Humanitas, LXIX, 2014, 4-5, pp. 622-630). 
<smiles>[As]</smiles> 